\title{
Are Health Care Expenditures and Personal Disposable Income Characterised by Asymmetric Behaviour? Evidence from US State-Level Data
}

\author{
Mulatu F. Zerihun, Tshwane University of Technology, Pretoria, South Africa \\ Juncal Cunado*, University of Navarra, Pamplona, Spain \\ Rangan Gupta, University of Pretoria, Pretoria, South Africa
}

\begin{abstract}
This paper examines the asymmetric behaviour of health care expenditure and disposable income in the 50 US states over the period 1966-2009 using nonparametric Triples test techniques. The results suggest that for 23 US states, real per capita health expenditures are characterized by asymmetric behaviour, while real per capita personal disposable income series exhibit asymmetric behaviour in 7 US states. Therefore, the main findings question the adequacy of linear models when modelling the behaviour of these two series.
\end{abstract}

JEL Code: C22, C32, H51, I18

Keywords: Asymmetric behaviour; Triples test; Per capita real healthcare expenditure; Per capita real personal disposable income; US states

$\begin{array}{ll}\text { Corresponding author: } & \text { Prof. Juncal Cunado } \\ & \text { University of Navarra } \\ & \text { School of Economics } \\ & \text { Edificio Amigos E-31080 } \\ & \text { Pamplona, Spain } \\ & \text { Email: jcunado@unav.es }\end{array}$

*Juncal Cuñado gratefully acknowledges financial support from the Ministerio de Economía y Competitividad (ECO2014-55496). 


\section{Introduction}

The proportion of national economies spent on health care in most modern industrialised countries has risen steadily over the past years. The reasons often mentioned for such ascending pattern are coincident with improving technology, available health insurance coverage, aging population and price inflation. The level of health care expenditures has always been among the main concerns of governments, policy makers, trade unions and citizens of the US (Freeman, 2003; Panopoulou and Pantelidis, 2013). US health care expenditures are by far highest in the world placing healthcare reform at the center of political and economic debates (Blavin et al., 2012; Guemmegne et al., 2014). For example, in 2013, \$2.9 trillion was spent on health care in the US (Hartman et al., 2014). Health spending accounted for 16.9\% of GDP in US in 2012 with the highest share among OECD countries and more than 71/2 percentage points above the OECD average of 9.3\% (OECD Health Statistics, 2014). In contrast to most OECD countries, health spending in the US is split evenly between public and private sources. In $2012,48 \%$ of health spending in the US was publicly financed, well below the average of $72 \%$ in OECD countries. Furthermore, the health spending is projected to grow at an average rate of 5.8\% from 20122022, $1.0 \%$ point faster than expected average annual growth in the GDP. In a recent study Caporale et al. (2015) summarise that the disposable income, together with other demand and supply factors such as medical technological progress or demographic trends, is one of the key drivers of healthcare demand and therefore expenditure.

Given such a huge magnitude of expenditure on health and its policy implications, it is relevant to examine the statistical behaviour of such macroeconomic variables. The behaviour of US total healthcare expenditure is complex and difficult to model (Guemmenge et al., 2014). So far, most studies have focused on modelling the economic characteristics of health expenditures. Such analyses are not sufficient since such theoretical models estimated and tested on the assumption of symmetric business cycles and linear data generating process. Consequently, if the disturbances are not symmetric, the results from unit-root and cointegration tests will be spurious (Narayan, 2009).

Empirical findings on asymmetric behaviour business cycles are at best mixed; while some find symmetrical behaviours, others asymmetric behaviour (Narayan, 2009; Chirila and 
Chirila, 2012). Such mixed findings are due to the fact that a variety of methodologies are applied to different countries in different time periods (Peiro, 2004). Similarly, there are also inconsistencies in the empirical findings of analyses of US national health care expenditures as justified by Getzen (2013).

This paper examines the asymmetric behaviour of healthcare expenditure and personal disposable income in the 50 US states over the period 1966-2009 using nonparametric Triples test techniques. Three main reasons explain the use of Triples test. First, following Narayan (2009), Triples tests allow us know the deepness and steepness asymmetry in the disposable income and health care expenditures. Second, Triples test methods are more efficient than many other methods used in the literature to detect asymmetry. Third, Triples test is asymptotically distribution free, which means that the outliers and changes in the variance of the distribution of the time series cannot affect the test (Narayan, 2009; Zerihun et al., 2014). To the best of our knowledge this study is the first attempt to test for asymmetric behaviour of these relevant variables at US state level using nonparametric Triples test.

The rest of the paper is organized as follows. The following section presents the literature review on asymmetric behaviour of income and health care expenditures and on the nonparametric methodology employed in this study. Section 3 defines the data set and presents the empirical results. Finally, Section 4 concludes.

\section{Literature review and methodology}

\subsection{Literature review}

The relationship between health care expenditures and disposable income has been extensively examined given its important policy implications (see, for example, Gerdtham and Lothgren, 2000; Di Matteo, 2003; Narayan, 2006, 2009; Baltagi and Moscone, 2010; Freeman, 2012 and, recently, Caporale et al., 2015). Most recent studies attempt to analyse such a relationship using parametric methods (see, for example, Wang, 2009; Freeman, 2012; Acemoglu et al., 2013; Yavuz et al., 2013; Caporale et al., 2015, among others). For example, Gerdtham and Lothgren (2000) tested a long run relationship between health expenditure and income using cointegration techniques. In another study, Narayan (2006) analyzed whether shocks have a permanent effect 
or a transitory effect on health care expenditure and income. Recently, Caporale et al. (2015) focus on health expenditure and income proposing fractional integration techniques. All the previous analyses are based on the assumption of symmetric business cycles and linear data generating process, so that their main conclusions rely on this assumption and could not be valid under asymmetric business cycles.

In a previous paper, Narayan (2009) proposed a nonparametric Triples test to study asymmetric per capita health expenditures and per capita GDP for 11 OECD countries. In this study we also use a nonparametric Triples test as described in the next section. Triples test was first developed by Randles et al. (1980) and later introduced to the economics literature by Verbrugge (1997) and Razzak (2001), respectively. In this paper, and following Narayan (2009), we also propose to use Triples test to model health care expenditures and income.

There is a general believe that most economic variables exhibit asymmetric behaviours. In the business cycle literature, there are two types of asymmetric behaviour: deepness (transversal) and steepness (longitudinal). ${ }^{1}$ A deep asymmetry arises when the series remains above trend for longer periods than below trend, whereas cycle troughs are further below trend, in absolute value, than the cycle peaks are above trend. In contrast the steepness asymmetry is characterized by steeper contractions in a series than expansions over the business cycle (Panopoulou and Pantelidis, 2013).

\subsection{Methodology: the Triples test}

Triples test was initially developed by Randles et al. (1980). To perform the Triples test, we face the immediate problem of decomposing the series into trend and cyclical components. To estimate deepness asymmetry, the series needs to be decomposed and de-trended to leave only the cyclical component of the series. Despite its limitations, we use the Hodrick-Prescott filter to detrend the time series (Narayan, 2009; Chirila and Chirila, 2012; Zerihun et al., 2014).

\footnotetext{
${ }^{1}$ Ramsey and Rothman (1996) classify asymmetry into longitudinal and transversal. They defined longitudinal asymmetry as asymmetry in the direction of the movement of the business cycle. In a similar manner, they defined transversal asymmetry as asymmetry orthogonal to the direction of the movement of the business cycle. Steepness would be a longitudinal asymmetry while deepness would be an example of transversal asymmetry.
} 
Likewise, to estimate the steepness asymmetry we used first differenced data. We then apply the Triples test to evaluate the symmetry of the classical cycles.

Intuitively, the Triples test counts all possible triples from a sample of size $N$ (i.e., $\left(\begin{array}{l}N \\ 3\end{array}\right)$ combinations) of a univariate time series. When most of the triples are right-skewed, the time series said to be asymmetric. If $i, j$ and $k$ are three distinct integers such that $1 \leq i, j, k \leq N$, the triple of observations $x_{i}, x_{j}, x_{k}$ forms a right triple or skewed to the right if the middle observation is closer to the smallest observation than it is to the largest observation. This is illustrated by:

Right triple

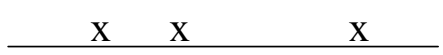

Left triple

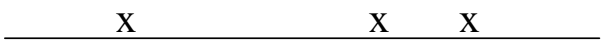

Formally, let $x_{i}, \ldots, x_{N}$ denote a random sample drawn from $F(x-\theta)$ where $F(\cdot)$ is a cumulative distribution function for a continuous population with $F(0)=\frac{1}{2}$ and $\theta$ is the median of the $x$ population.

Let,

$f^{*}\left(x_{i}, x_{j}, x_{k}\right)=\left[\operatorname{sign}\left(x_{i}+x_{j}-2 x_{k}\right)+\operatorname{sign}\left(x_{i}+x_{k}-2 x_{j}\right)+\operatorname{sign}\left(x_{j}+x_{k}-2 x_{i}\right)\right]^{3}$

where $\operatorname{sign}(u)=-1,0$ or or equal to when $\mathrm{u}$ is equal, greater, or smaller than 0 .

Then we say $x_{i}, x_{j}, x_{k}$ forms a right triple if $f^{*}\left(x_{i}, x_{j}, x_{k}\right)=\frac{1}{3}$. Note that $f^{*}\left(x_{i}, x_{j}, x_{k}\right)$ can only assume the values $1 / 3,0,1 / 3$. We define a left triple (looks skewed to the left) as any $\left(x_{i}, x_{j}, x_{k}\right)$ for which $f^{*}\left(x_{i}, x_{j}, x_{k}\right)=\frac{-1}{3}$ (again see the figure above). Finally, when $f^{*}\left(x_{i}, x_{j}, x_{k}\right)=0$, the triple is neither right nor left skewed. This last event, however, has probability zero when sampling from a continuous population. The proposed test statistics is then the $U$ statistics given by: 
$\hat{\eta}=\left(\begin{array}{c}N \\ 3\end{array}\right)^{-1} \sum_{i<j<k} f^{*}\left(x_{i}, x_{j}, x_{k}\right)$.

So that

$\hat{\eta}=\frac{[(\text { number of right triples })-(\text { number of left triples })]}{\left[3\left(\begin{array}{c}N \\ 3\end{array}\right)\right]}$,

It follows from Hoeffding (1948) that this is a U statistics estimate

$E(\hat{\eta})=\eta=\operatorname{Pr}\left\{X_{1}+X_{2}-2 X_{3}>0\right\}-\operatorname{Pr}\left\{X_{1}+X_{2}-2 X_{3}<0\right\}$,

with

$\operatorname{var}(\hat{\eta})=\left(\begin{array}{l}N \\ 3\end{array}\right)^{-1} \sum_{c=1}^{3}\left(\begin{array}{l}3 \\ c\end{array}\right)\left(\begin{array}{cc}N & -3 \\ 3 & -c\end{array}\right) \zeta_{c}$

where

$\zeta_{c}=\operatorname{var}\left[f_{c}^{*}\left(x_{1}, \ldots, x_{c}\right)\right]$

and

$f_{c}^{*}\left(x_{1}, \ldots, x_{c}\right)=E\left[f^{*}\left(x_{1}, \ldots, x_{c}, x_{c+1}, \ldots, x_{3}\right)\right]$.

Letting $\sigma_{A}^{2}=9 \zeta_{1}$ and since $\sigma_{N}^{2}=\sigma_{A}^{2}+\sigma(1)$, Randles et al. (1980) use the Slutsky theorem to show that $N^{1 / 2}=(\hat{\eta}-\eta) / \sigma_{A}$ also has a standard normal limiting distribution. We now discuss the appropriate hypotheses to be tested. First note that if the underlying distribution is symmetric, $X_{1}+X_{2}-2 X_{3}$ has the same distribution as $-X_{1}-X_{2}+2 X_{3}$ and therefore, $\eta=0$. Hence we can use $\hat{\eta}$ as a statistic for testing, 
$H_{0}: \hat{\eta}=0$ versus $H_{1}: \hat{\eta} \neq 0$

This is a two-sided test, but could possibly be a one-sided test. This test is used to test the hypothesis that the distribution is symmetric around the unknown median $\theta$ against a broad class of asymmetric alternatives. The Triples test interpretation goes with hypothesis testing in equation (8). If we have significant evidence to reject the null hypothesis it means asymmetry. If we fail to reject the null hypothesis the opposite holds true.

The simple nature of $f^{*}(\cdot)$ makes $\zeta_{1}, \zeta_{2}$ and $\zeta_{3}$ expressible in terms of probabilities, and thus it is possible to use $U$ statistics to estimate these quantities consistently as follows:

$\zeta_{1}=\operatorname{var}\left[f_{1}^{*}\left(x_{1}\right)\right]$ with $f_{1}^{*}\left(x_{1}\right)=E\left[f_{1}^{*}(\cdot)\right]$

$\zeta_{1}=N^{-1} \sum_{i=1}^{N}\left(f_{1}^{*}\left(x_{i}\right)-\hat{\eta}\right)^{2}$,

where

$f_{1}^{*}\left(x_{i}\right)=\left(\begin{array}{c}N-1 \\ 2\end{array}\right) \sum_{\substack{j<k \\ j \neq i \neq k}} \sum f_{1}^{*}\left(x_{i}, x_{j}, x_{k}\right)$.

Similarly,

$\zeta_{2}=\frac{1}{\left(\begin{array}{c}N \\ 2\end{array}\right)} \sum_{j<k} \sum\left(f_{2}^{*}\left(x_{i}, x_{k}\right)-\hat{\eta}\right)^{2}$,

where

$f_{2}^{*}\left(x_{j}, x_{k}\right)=\frac{1}{N-2} \sum_{\substack{i=1 \\ j \neq i \neq k \\ i \neq k}} \sum f^{*}\left(x_{i}, x_{j}, x_{k}\right)$,

and 
$\zeta_{3}=\frac{1}{9}-\hat{\eta}^{2}$

Replacing each with $\zeta_{i}$ and $\hat{\zeta}_{i}$ in the expressions $\sigma_{N}$ and $\sigma_{A}$ gives the estimators $\hat{\sigma}_{N}$ and $\hat{\sigma}_{A}$. Both estimators are consistent because each $\hat{\zeta}_{i}$ is written as a linear combination of $U$ statistics.

To test the hypothesis in (8), the Triples test is defined based on $T_{1}=n^{1 / 2} \hat{\eta} / \hat{\sigma}_{N}$ and an associated test based on $T_{2}=n^{1 / 2} \hat{\eta} / \hat{\sigma}_{A}$ so that they reject $H_{0}$ as $\left|T_{i}\right|>Z_{(\alpha / 2)}, i=1,2$ and $Z_{(\alpha / 2)}$ is as the upper percentile of the standard normal distribution. Note that these tests are asymptotically distribution free provided only that the underlying distribution is not degenerate. Although we have illustrated how to construct an asymptotically distribution-free test of (8), we should keep in mind that the parameter $\eta$ is defined in terms of the distribution of the triple $X_{1}, X_{2}$ and $X_{3}$ rather than the original $F$ distribution.

\section{Data and empirical results}

\subsection{Data}

For our empirical analysis, we use annual data on healthcare expenditures from 1966 to 2009 for 50 US states. Data were obtained from the Center for Medicare and Medicaid Services Health Expenditures by state of residence. This database reports total personal health care spending by state and by service. Data on nominal personal disposable income for the same time span are obtained from the regional database of the Bureau of Economic Analysis. Data on both these variables are expressed in per capita terms, by dividing with population figures, obtained also from the regional database of the Bureau of Economic Analysis.

Given that state level CPI is not available for the entire period under study, the nominal per capita health care expenditure and the per capita nominal personal disposable income are converted to their real values by deflating with the aggregate US CPI. Finally, we transform the data into their natural logarithmic values. The data on real per capita health expenditures and personal disposable income for the 50 US states are obtained from Freeman (2012). For full 
description of the data set see Freeman $(2012){ }^{2}$ The same data set is already used by a recent study by Caporale et al. (2015).

\subsection{Empirical results}

Initially, we run Triples test using per capita health care expenditure. The results on asymmetry or otherwise in real per capita health expenditures for a panel of 50 US states are presented in Table 1. In panels (a) and (b) we present the results on deepness (asymmetry in the levels around a de-trended series, based on the Hodrick and Prescott (1997) filter) and the results on steepness (asymmetry in the first difference of the series, i.e., the growth rates, given that the variables are in their natural logarithmic form), respectively. Note that, if the first differenced data are asymmetric, then it implies that contractions are steeper than expansions (Narayan, 2009), while asymmetry of a detrended series implies that the length of the trough is deeper than the height of the peak (Sichel, 1993). The Triples test is also able to distinguish between negative and positive asymmetry. Positive steepness suggests that the series has undergone rapid increases over a short period of time, and slow gradual decreases over a long span. Negative steepness, on the other hand, would be indicative of the fact that the series has fallen rapidly and has risen slowly (Razzak, 2001). The positive deepness implies cyclical peaks are greater than the troughs, while negative deepness is indicative of the fact that troughs are higher than the peaks (Cook, 2006). ${ }^{3}$

Our results on the analysis of per capita health expenditure are as follows. First, we find statistically significant evidence of deepness asymmetry in the case of two sates only; namely, Kansas with positive asymmetry at $10 \%$ level and Wisconsin negative at $5 \%$ level. Second, we find statistically significant evidence of steepness asymmetry in 21 states. Namely; Alaska (at $1 \%$ level), Arkansas (at 5\% level), Delaware (at 5\% level), Iowa (at 1\% level), Kentucky (at 1\% level), Louisiana (at 5\%level), Maine (at 1\% level), Maryland (at 5\% level), Massachusetts (at 10\% level), Mississippi (at 5\% level), New Hampshire (at 10\% level), New Mexico (at 1\% level), Oregon at (5\% level), Rhodes Island (at 10\% level), South Carolina (at 5\% level), South Dakota (at 5\% level), Texas (at 10\% level), and Vermont (at 1\% level), respectively. Third, we find negative steepness asymmetry in per capita health expenditures of state of Delaware,

\footnotetext{
${ }^{2}$ We would like to thank Donald G. Freeman, Sam Houston State University, for providing the dataset.

${ }^{3}$ All computations were done using the publicly available MATLAB codes written by Jos van der Geest.
} 
Kentucky, Louisiana, Maine, Maryland, Massachusetts, Mississippi, New Hampshire, Oregon, Rhodes Island and South Carolina implying that health expenditures in these countries falls rapidly and rises gradually. This indicates that for those states economic recovery happens far slower than the preceding downswing. Overall we find that in a total of 23 states has exhibited asymmetric behavior in their real per capita health expenditures from 1996-2009. In the rest of 27 states we do not find any evidence of any form asymmetric behaviour in real per capita health expenditures.

\section{< Insert Table 1 about here >}

We report the results on asymmetric behaviour of real per capita disposable personal income in Table 2. The results are organized as in the case of per capita health care expenditures. The main findings can be summarized as follows. First, only in the case of Idaho State we find significant evidence for deepness asymmetry in per-capita health expenditures at $10 \%$ level. Second, we find six states with significant evidence of steepness asymmetric behaviour. These states are Arizona, Maine and Nevada, each at $10 \%$ level; Missouri and Utah each at $5 \%$ level and the State of Vermont has exhibited steepness asymmetry at $1 \%$ level of significance. All the above mentioned seven states have exhibited significant negative steepness, except Idaho with negative deepness asymmetry. Negative symmetry implies that real per capita disposable personal income in these states falls rapidly, but rises very slowly. Meanwhile, for the remaining 43 states, we do not find any evidence of any form asymmetric behavior in real per capita disposable personal income. Previous results are in line with Narayan (2009) which found that 6 out of 11 OECD countries present asymmetric behaviour in per capita health care expenditure and income per capita.

\section{< Insert Table 2 about here $>$}

\section{Conclusions}

Results and interpretations from theoretical models estimated and tested on the assumption of symmetric business cycles and linear data generating process will be unauthentic if the disturbances are not symmetric. Inaccurate results from such theoretical applications can be very 
costly in the context of US where there is substantial proportion of national economies spent on health care. Clearing such doubts for the sake of appropriate policy exercise in US is innovative by its own right. For these reasons we tested for possible asymmetric behaviour of per capita health expenditures and per capita disposable income for a panel of 50 US states using the nonparametric Triples test.

Our main findings suggest the following. The results suggest that for 23 US states, real per capita health expenditures are characterized by asymmetric behaviour, while real per capita disposable personal income series exhibit asymmetric behaviour in 7 US states.

To sum up, asymmetry exists in both data series implying that using linear models for income and health expenditure analysis is problematic. Particularly, empirical estimations and tests carried out on per capital disposable income expenditures using models based on the assumption of symmetric business cycles and linear data generating process are questionable. Therefore, for empirical analysis using US state level data on per capita health expenditures and real per capita disposable personal income, we suggest the use of nonlinear models or models that capture asymmetric disturbances that are likely to be more appropriate than standard linear structural or time series models. The findings in this study are in line with the findings previously recommended by Narayan (2009) for selected OECD countries. 


\section{References}

Acemoglu, D., Finkelstein, A. and Notowidigdo, M., (2013). Income and health spending: Evidence from oil price shocks. The Review of Economics and Statistics 95, 10791095.

Baltagi B., Moscone, F., (2010). Health care expenditure and income in the OECD reconsidered: evidence from panel data. Economic Modelling 27, 804-811.

Blavin, F., Blumberg, L., Waidmann, T., Phadera, L., (2012). Trends in US health care spending leading up to health reform. The Urban Institute, Robert Wood Johnson Foundation, Washington DC.

Caporale, G.M., Cunado, J., Gil-Alana, L.A, Gupta, R., (2015). The relationship between healthcare expenditure and disposable personal income in the US states: A fractional integration and cointegration analysis. CESIFO Working Paper No. 5407.

Chirila, V., Chirila, C., (2012). Testing business cycles asymmetry in Central and Eastern European countries. Modern Economy 3, 713-717.

Cook, S., (2006). A Disaggregated Analysis of Asymmetrical Behaviour in the UK Housing Market. Urban Studies, 43(11), pp. 2067-2074.

Di Matteo, L., (2003). The income elasticity of health care spending. A comparison of parametric and nonparametric approaches. European Journal of Health Economics 4, 20-29.

Getzen, T.E. (2013). Modeling Medical Cost Trends for Advancing Age in the Long Run. Available at SSRN: http://ssrn.com

Freeman, D.G., (2003). Is health care a necessity or a luxury? Pooled estimates of income elasticity from US state-level data, Applied Economics, 35:5, 495-502.

Freeman, D.G., (2012). Is health care a necessity or a luxury? New evidence from a panel of US state-level data. Sam Houston State University, Economics and International Business Working Paper No. 12-03.

Guemmegne, J.T., Kengwoung-Keumo, J.J., Tabatabai, M.A., Singh, K.P., (2014). Modeling the dynamics of the US healthcare expenditure using a hyperbolastic function. Advances and Applications in Statistics 42, 95-117.

Hartman, M., Martin, A., Lassman, D., Catlin, A., (2015). National health spending in 2013: Growth slows, remains in step with the overall economy. Health Affairs 34, 150-160. 
Hodrick, R., Prescott, E.C., (1997). Postwar business cycles: An empirical investigation. Journal of Money, Credit and Banking 29, 1-16.

Hoeffding, W., (1948). A class of statistics with asymptotically normal distributions. Annals of Statistics, 19:293-325.

OECD Health Statistics (2014). How does the United States compare? Available at: www.oecd.org/health/healthdata.

Moscone F., Tosetti, E., (2010). Health expenditure and income in the United States. Health Economics 19, 1385-1403.

Narayan, P.K., (2009). Are health expenditures and GDP characterized by asymmetric behaviour? Evidence from 11 OECD countries. Applied Economics 41, 531-536.

Panopoulou, E. ,T. Patenlidis, T., (2013). Cross-state disparities in US health care expenditures. Health Economics 22, 451-465.

Peiro, A., (2004). Are business cycles asymmetric? Some European evidence. Applied Economics 36, 335-342.

Ramsey, J., Rothman, P., (1996). Time irreversibility and business cycle asymmetry. Journal of Money, Credit and Banking, 28, 1-21.

Randles, R.H., Flinger, M.A., Policello, G.E., Wolfe, D.A., (1980). An asymptotically distribution free test for symmetry versus asymmetry. Journal of the American Statistical Association 75, 168-172.

Razzak, W.A., (2001). Business cycle asymmetries: International evidence. Review of Economic Dynamics 4, 230-243.

Sichel, D.E., (1993). Business cycle asymmetry: A deeper look. Economic Inquiry XXXI, 224-236.

Verbrugge, R., (1997). Investigating cyclical asymmetries. Studies in Nonlinear Dynamics and Econometrics 2, 15-22.

Wang, Z., (2009). The convergence of health care expenditure in the US states. Health Economics 18, 55-70.

Zerihun, M.F., Breitenbach, M.C., Kemegue, F., (2014). Greek wedding in SADC? Testing for structural symmetry toward SADC monetary integration. The African Finance Journal, $16(2), 16-33$. 
Table 1. Asymmetric behaviour of real per capita health expenditure

\begin{tabular}{|c|c|c|c|c|}
\hline & \multicolumn{2}{|c|}{$\begin{array}{l}\mathrm{H}_{0}: \eta=0 \\
\text { Deepness }\end{array}$} & \multicolumn{2}{|c|}{$\begin{array}{l}\mathrm{H}_{0}: \eta=0 \\
\text { Steepness }\end{array}$} \\
\hline & U statistics & p-value & U statistics & p-value \\
\hline Alabama & 0.5475 & 0.5841 & 0.695 & 0.4871 \\
\hline Alaska & 0.0922 & 0.9265 & 5.6250 & $0.0000 * * *$ \\
\hline Arizona & -0.3675 & 0.7132 & 0.5538 & 0.5797 \\
\hline Arkansas & 1.2331 & 0.2175 & 2.2732 & $0.0230 * *$ \\
\hline California & -0.8310 & 0.4059 & 2.2732 & 0.2028 \\
\hline Colorado & 0.6660 & 0.5054 & 0.8568 & 0.3915 \\
\hline Connecticut & 0.1714 & 0.8639 & 1.5455 & 0.1222 \\
\hline Delaware & -0.0447 & 0.9644 & 2.4747 & $0.0133 * *$ \\
\hline Florida & -1.1277 & 0.2594 & 1.2556 & 0.2093 \\
\hline Georgia & -1.1469 & 0.2514 & 0.1949 & 0.8455 \\
\hline Hawaii & -0.6929 & 0.4884 & 0.7449 & 0.4563 \\
\hline Idaho & -0.0279 & 0.9777 & -0.1207 & 0.9039 \\
\hline Illinois & 0.5036 & 0.6145 & 1.1813 & 0.2375 \\
\hline Indiana & -0.6505 & 0.5154 & 0.0399 & 0.9681 \\
\hline Iowa & 0.2721 & 0.7855 & 1.6622 & $0.0965^{*}$ \\
\hline Kansas & 1.7174 & $0.0859 *$ & 1.1145 & 0.2650 \\
\hline Kentucky & 0.8579 & 0.3909 & 1.9122 & $0.0559 *$ \\
\hline Louisiana & -0.7414 & 0.4584 & 2.1408 & $0.0323 * *$ \\
\hline Maine & -0.1868 & 0.8518 & 3.798 & $0.0001 * * *$ \\
\hline Maryland & -1.5117 & 0.1306 & 2.4921 & $0.0127 * *$ \\
\hline Massachusetts & -0.4274 & 0.6691 & 1.8876 & $0.0591 *$ \\
\hline Michigan & -1.2318 & 0.2180 & 0.9263 & 0.3543 \\
\hline Minnesota & -0.6521 & 0.5143 & 0.3801 & 0.7039 \\
\hline Mississippi & -0.4420 & 0.6585 & 2.1026 & $0.0355 * *$ \\
\hline Missouri & 0.1437 & 0.8857 & 0.4787 & 0.6322 \\
\hline Montana & 0.1290 & 0.8974 & 1.3368 & 0.1813 \\
\hline Nebraska & -0.6104 & 0.5416 & 1.2181 & 0.2232 \\
\hline Nevada & 0.0873 & 0.9304 & -0.7001 & 0.4839 \\
\hline New Hampshire & -0.8549 & 0.3926 & 1.9242 & $0.0543^{*}$ \\
\hline New Jersey & -0.0129 & 0.9897 & 1.4671 & 0.1423 \\
\hline New Mexico & 0.0077 & 0.9939 & 2.6353 & $0.0084 * * *$ \\
\hline New York & -0.2673 & 0.7892 & 0.9619 & 0.3361 \\
\hline North Carolina & -1.5962 & 0.1104 & 0.1015 & 0.9192 \\
\hline North Dakota & 0.0493 & 0.9607 & 0.4305 & 0.6668 \\
\hline Ohio & -0.5019 & 0.6158 & 1.4050 & 0.1600 \\
\hline Oklahoma & 0.2011 & 0.8406 & 1.5246 & 0.1274 \\
\hline Oregon & -1.5636 & 0.1179 & 2.0308 & $0.0423 * *$ \\
\hline
\end{tabular}




\begin{tabular}{lcccc}
\hline Pennsylvania & 0.2065 & 0.8364 & 0.2140 & 0.8306 \\
Rhode Island & -0.4054 & 0.6852 & 1.8336 & $0.0667^{*}$ \\
South Carolina & -0.0481 & 0.9616 & 2.5212 & $0.0117^{* *}$ \\
South Dakota & 0.6886 & 0.4911 & 2.3123 & $0.0208^{* *}$ \\
Tennessee & -0.4062 & 0.6846 & 0.8475 & 0.3967 \\
Texas & 0.3071 & 0.7588 & 1.6526 & $0.0984^{*}$ \\
Utah & -0.5517 & 0.5812 & 1.3669 & 0.1717 \\
Vermont & 1.3393 & 0.1805 & 3.9035 & $0.0001^{* * *}$ \\
Virginia & 0.4032 & 0.6868 & 2.1339 & 0.0328 \\
Washington & 0.5918 & 0.5540 & 2.2899 & $0.0220^{* *}$ \\
West Virginia & -0.2448 & 0.8066 & 3.6664 & $0.0002^{* * *}$ \\
Wisconsin & -2.2977 & $0.0216 * *$ & 1.2790 & 0.2009 \\
Wyoming & -0.5075 & 0.6118 & 1.8708 & $0.0614^{*}$ \\
\hline
\end{tabular}

Note: ${ }^{* * *}$, and $* * *$ denote statistical significance at the 10,5 , and $1 \%$ levels, respectively. The significant $\mathrm{p}$-values show that the null hypothesis is rejected which implies asymmetry in the series. 
Table 2. Asymmetric behaviour of real per capita disposable personal income

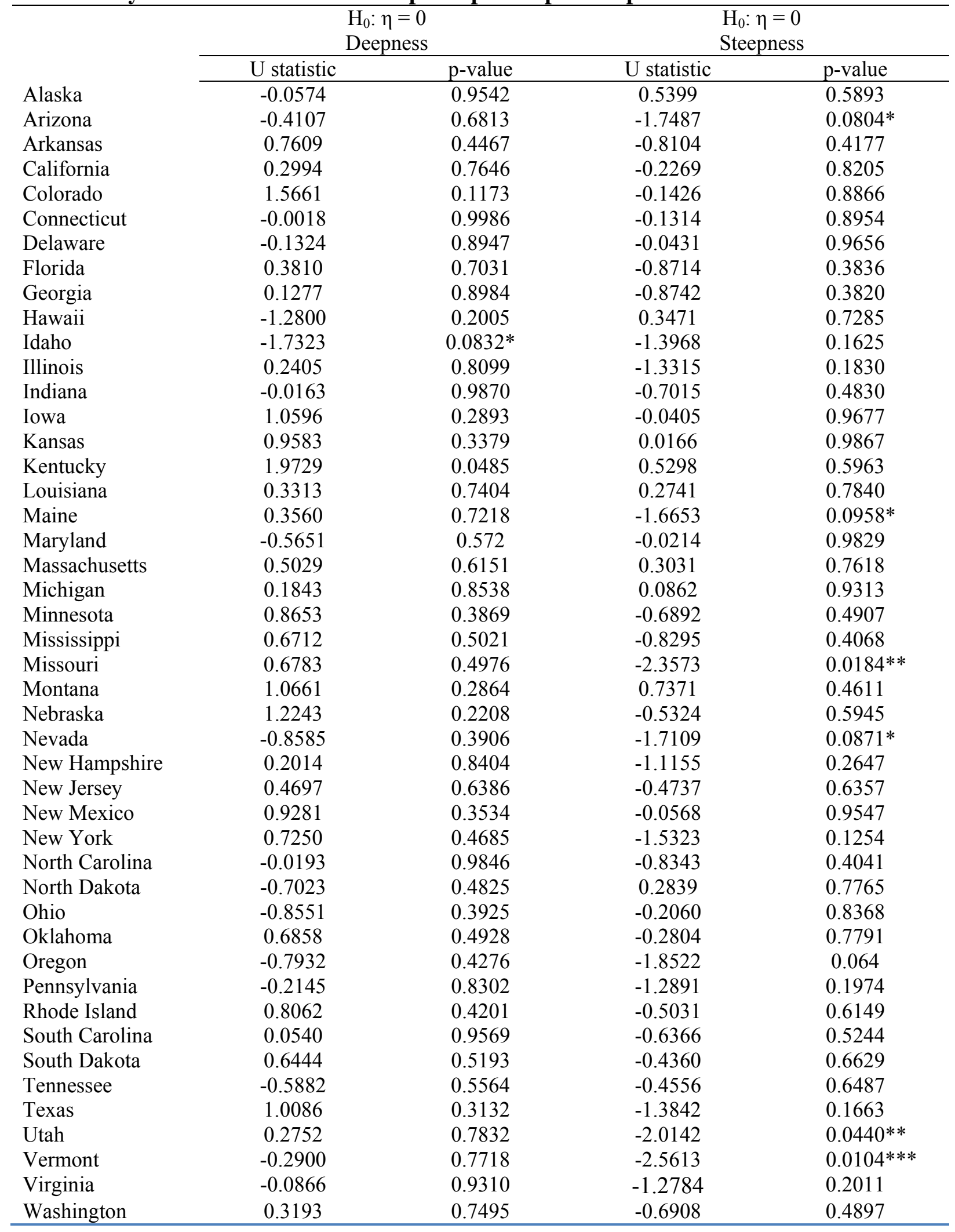




\begin{tabular}{lllll}
\hline West Virginia & -0.3455 & 0.7297 & -0.5744 & 0.5657 \\
Wisconsin & -0.4423 & 0.6583 & -0.7751 & 0.4383 \\
Wyoming & -0.2075 & 0.8356 & -0.1825 & 0.8552 \\
\hline
\end{tabular}

Note: ${ }^{*}, * *$ and $* * *$ denote statistical significance at the 10,5 , and $1 \%$ levels, respectively. The significant $\mathrm{p}$-values show that the null hypothesis is rejected which implies asymmetry in the series. The " $\eta$ " values are not reported for we used "U" statistics for the interpretation of the results. 